\title{
BREVE ENSAIO CRÍTICO SOBRE A HERMENÊUTICA METODOLÓGICA E SUA “SUPERAÇÃO” PELA HERMENÊUTICA FILOSÓFICA NO DIREITO PENAL ${ }^{*}$
}

\section{A BRIEF CRITICAL TEST ON METHODOLOGICAL HERMENEUTICS AND THEIR "OVERCOMING" BY PHILOSOPHICAL HERMENEUTICS IN CRIMINAL LAW}

\section{Ricardo Fernandes Maia ${ }^{\star \star}$}

Resumo: O operador do Direito sempre se viu diante de um desafio, qual seja a interpretação na norma e, consequentemente, a solução do caso apresentado perante o órgão judicial. Por muito tempo este operador do Direito trabalhou diante de uma hermenêutica assentada sobre uma matriz metodológica, que tinha a lei como eixo do discurso do Direito. Este entendimento se viu superado, uma vez que o ordenamento jurídico se mostrou insuficiente perante a complexidade, a evolução e a dinâmica dos fenômenos sociais, sempre em evolução. Neste cenário confuso e controvertido, surge a hermenêutica filosófica, que altera o paradigma antigo, trazendo para o operador do Direito uma nova ótica hermenêutica. Nesta nova hermenêutica, a lei deixa de ser o centro do Direito, agora ocupado pela dignidade da pessoa humana operador do Direito encontra uma nova missão, compreender o caso concreto e decidir a luz da dignidade humana, onde o Direito passa a ser apenas mais um instrumento posto à sua disposição, e não o único.

Palavras-chave: Direito; hermenêutica; dignidade; pessoa.

Abstract: The operator of the law has always faced a challenge, namely the interpretation in the standard and, consequently, the solution of the case presented before the judicial body. For a long time, this operator of the Law worked on a hermeneutic based on a methodological matrix, which had the law as the axis of the discourse of Law. This understanding was overcome, since the legal order proved insufficient in the face of the complexity, the evolution and the dynamics of social phenomena, always evolving. In this confused and controversial scenario, philosophical hermeneutics arises, which alters the old paradigm, bringing to the operator of law a new hermeneutical view. In this new hermeneutics, the law ceases to be the center of law, now occupied by the dignity of the human person operator of the law finds a new mission, understand the concrete case and decide the light of human dignity, where the law becomes just one more instrument available to them, and not the only one.

\footnotetext{
"Uma versão modificada deste artigo foi publicada no livro "Estudos em Homenagem ao Professor Doutor José Rogério Moura de Almeida Filho", de coordenação de Cleyson de Moraes Mello, José Rogério Moura de Almeida Neto e Regina Pentagna Pentrillo.

Mestre em Direito pela Faculdade Presidente Antônio Carlos (UNIPAC). Professor do Curso de Direito do Centro Universitário de Volta Redonda (UNIFOA).
} 
Keywords: Law; hermeneutics; dignity; person. 


\title{
1 INTRODUÇÃO
}

A dogmática hermenêutica, na antiga visão metodológica, possuía a função de apontar as regras e princípios para a determinação da interpretação das normas e o correto entendimento dos seus textos.

\begin{abstract}
Quando o Direito é aplicado por um órgão jurídico, este necessita fixar o sentido das normas que vai aplicar, tem de interpretar estas normas. A interpretação é, portanto, uma operação mental que acompanha o processo de aplicação do Direito no seu progredir de um escalão superior para um escalão inferior. $\mathrm{Na}$ hipótese em que geralmente se pensa quando se fala em interpretação, na hipótese da interpretação da lei, deve responder-se à questão de saber qual o conteúdo que há de se dar a norma individual de uma sentença judicial ou de uma resolução administrativa, norma essa a deduzir da norma geral da lei na sua aplicação a um caso concreto. (KELSEN, 2006, p. 387).
\end{abstract}

Cabia então ao operador do Direito, ainda atrelado a uma hermenêutica metodológica, equivocadamente, interpretar a norma, colocando-a frente ao caso concreto, pois o jurista funcionava como um elo entre a norma e à "realidade". A norma penal não fugia a esta regra uma vez que como integrante do ordenamento jurídico requeria uma interpretação apurada por parte do operador do Direito. Tanto as normas controversas quanto as normas claras mereciam uma interpretação cautelosa, até porque, o Direito Penal se trata do instrumento de controle social mais forte em razão da sanção penal.

Cumpre ressaltar que o desafio de interpretar a norma penal se mostrou tormentoso ao longo dos tempos. Isto porque a maneira metodológica utilizada de se interpretar a norma penal deflagrou várias interpretações controvertidas para um caso concreto. Assim sendo, conforme a ideologia propulsora da operação mental do aplicador do Direito, dentro de uma concepção de hermenêutica metodológica, este deveria escolher, por meio dos métodos interpretativos, dentre as possíveis interpretações, aquela que melhor se adequasse ao fato. Aqui se via uma porta aberta para o subjetivismo.

A norma penal, dentro de uma hermenêutica metodológica, devia ser interpretada como qualquer outra, segundo os processos hermenêuticos, com as devidas restrições impostas pelo princípio da legalidade.

Nosso trabalho, neste momento, tem por finalidade, somente por uma questão histórica, esclarecer os principais métodos de interpretação da norma penal, 
dentro de uma superada hermenêutica metodológica, bem como incutir a importância de um pensamento minimalista nas questões controvertidas que envolviam a atividade hermenêutica.

No contexto da hermenêutica metodológica, toda a lei devia ser interpretada para ser aplicada, mesmo quando clara, porquanto não era condição da interpretação ser ela obscura. "Dessa forma, não procede o aforismo in claris non fit interpretatio, pois só a interpretando poder-se-á saber se ela é clara. Poder-se-ia dizer ser mais fácil a interpretação quando clara for a norma, mais difícil e penosa, quando obscura". (GUSMÃO, 1982, p. 269).

No sistema inquisitorial, em especial na fase em que se buscou retirar das mãos dos juízes parte da sua autoridade passando para o legislador o crédito no controle da aplicação do Direito, conforme ensinava Cesare Beccaria a respeito da proibição de qualquer tentativa de interpretação das leis criminais. Estas deveriam ser executadas segundo seu texto, a fim de que cada cidadão pudesse "calcular exatamente os inconvenientes de uma ação reprovável; e isso é útil, porque tal conhecimento poderia desviá-lo do crime". (BECCARIA, 1983, p. 38). Tal entendimento se devia ao fato da ideia de livrar o povo da prepotência e crueldade reinante no judiciário inquisitorial.

A interpretação, dentro da hermenêutica metodológica, consistia em abstrair da norma o seu verdadeiro significado, o seu conteúdo e alcance frente à realidade para aplicação no caso concreto.

Interpretar era um trabalho cognoscitivo. O ato da interpretação da norma penal tinha por objeto o conhecimento do significado da norma. Não se tratava somente de pesquisar a vontade do legislador, como queriam os subjetivistas, nem, simplesmente, buscar revelar a vontade objetiva da norma como queriam os objetivistas, pois o legislador não podia prever todas hipóteses que podiam ocorrer na vida em sociedade.

\footnotetext{
A "existência" de uma norma jurídica não é um fenômeno psicológico. Um jurista considera um estatuto "existente", mesmo quando os indivíduos que o criaram não mais querem o conteúdo do estatuto, ou, mais ainda, mesmo quando ninguém mais quer o seu conteúdo, pelo menos ninguém dentre os que tinham competência para criar o estatuto através de atos de vontade. $\mathrm{Na}$ verdade, é possível, e muitas vezes acontece efetivamente, que o estatuto "exista" numa época em que os responsáveis por sua criação já estão mortos e incapazes de ter qualquer tipo de vontade há muito tempo. Desse modo, o estatuto obrigatório não pode ser a vontade da mente dos
} 
indivíduos que o fazem, mesmo que 0 ato de vontade real seja necessário para a elaboração do estatuto. (KELSEN, 1992, p. 38).

A realidade coletiva evolui constantemente e a norma escrita é insuficiente para regular tantas mutações. Por isso, para a hermenêutica metodológica, cabia ao intérprete descobrir o conteúdo da norma em conformidade com o contexto em que se encontrava.

\begin{abstract}
Norma penal é a norma de Direito em que se manifesta a vontade do Estado na definição dos fatos puníveis e cominação das sanções. Definida assim é a norma incriminadora, norma penal em sentido estrito. Mas normas penais são também aquelas que completam o sistema penal com seus princípios gerais e dispõem sobre a aplicação e os limites das normas incriminadoras. (BRUNO, 2003, p. 117).
\end{abstract}

De fato, a norma penal, ainda dentro de uma visão hermenêutico metodológica, sobre a qual recaia o trabalho do hermeneuta não era somente a incriminadora, ou seja, aquela que definia a conduta que o Estado queria reprimir por ameaça de pena, mas também aquelas outras normas que integravam o organismo legislativo penal, como as normas permissivas que se traduziam em uma autorização para que a pessoa atuasse em determinada circunstância como é o caso, que ainda pode ser visto atualmente, das excludentes de ilicitude ${ }^{1}$.

São também sujeitas à interpretação de cunho metodológico aquelas normas explicativas que visam trazer ao Direito Penal alguma conceituação com a finalidade de facilitar ou até mesmo viabilizar a aplicação da norma penal incriminadora. Como exemplo de norma penal explicativa podemos citar aquela que traz o conceito de funcionário público para efeitos penais e que está regulada no art. 327 do Código Penal. É esta norma explicativa que permite a aplicabilidade dos tipos penais que tratam os crimes praticados por funcionários públicos contra a administração pública, sem ela tais dispositivos seriam inócuos ${ }^{2}$.

\footnotetext{
${ }^{1}$ Código Penal - Art. 23 - Não há crime quando o agente pratica o fato:

I - em estado de necessidade;

II - em legítima defesa;

III - em estrito cumprimento de dever legal ou no exercício regular de direito.

${ }_{2}^{2}$ Código Penal - Art. 327 - Considera-se funcionário público, para os efeitos penais, quem, embora transitoriamente ou sem remuneração, exerce cargo, emprego ou função pública.

$\S 1^{\circ}$ - Equipara-se a funcionário público quem exerce cargo, emprego ou função em entidade paraestatal, e quem trabalha para empresa prestadora de serviço contratada ou conveniada para a execução de atividade típica da Administração Pública.
} 
Por fim, existem normas complementadoras que visam integrar algum procedimento trazendo parâmetros ao aplicador do Direito, neste sentido, podemos citar o art. 59 do Código Penal que dispõem sobre as circunstâncias judiciais em que o magistrado deve apoiar-se para efetuar o cálculo da pena base, bem como definir o regime inicial de cumprimento de pena ${ }^{3}$.

Cumpre ressaltar que compete ao legislativo, por força constitucional, a função criadora das leis e ao magistrado compete a aplicação da lei, assim sendo, a criação se dá no campo abstrato e a aplicação no âmbito da concretude. Ocorre, todavia, que segundo os princípios que norteavam a hermenêutica metodológica, não competia ao juiz do caso concreto a função de criar as leis, mas sim de interpretá-las e dar-lhes o sentido de aplicação de acordo com os ideais que a inspiraram, entretanto, não se pode olvidar que quando o magistrado aplicava a lei ao caso concreto depois de ter retirado de sua norma o seu sentido acabava por conceber a "norma do caso concreto", surgindo então a controvérsia a respeito da função criadora da interpretação.

\begin{abstract}
A interpretação da lei penal é uma operação composta que exige estabelecer o significado abstrato (intenção) e o concreto ante o caso a resolver (aplicação) a lei penal não é carente de função; não devemos confundir função criadora e função criadora do Direito. Nem a jurisprudência, nem a doutrina são fontes do Direito Penal, razão pela qual a interpretação não poderá ser criadora do Direito. (COSTA, 2005, p. 422).
\end{abstract}

$\mathrm{Na}$ verdade, dentro da visão ultrapassada da hermenêutica metodológica, podemos identificar que 0 ato judicial pode-se traduzir em uma criação de uma norma de cunho individual tendo por base normas de caráter geral.

A doutrina tradicional considera como aplicação do Direito, antes de mais
nada, a decisão judicial, a função dos tribunais. Quando soluciona um
conflito entre duas partes, quando sentencia uma punição para um acusado,
o tribunal aplica, é verdade, uma norma geral do Direito estatutário ou
consuetudinário. Simultaneamente, no entanto, o tribunal cria uma norma
individual que estipula que uma sanção definida seja executada contra o
indivíduo definido esta norma individual está relacionada às normas gerais
assim como um estatuto está relacionado à constituição. Desse modo a

${ }^{3}$ Código Penal - Art. 59 - O juiz, atendendo à culpabilidade, aos antecedentes, à conduta social, à personalidade do agente, aos motivos, às circunstâncias e consequências do crime, bem como ao comportamento da vítima, estabelecerá, conforme seja necessário e suficiente para reprovação e prevenção do crime:

I - as penas aplicáveis dentre as cominadas;

II - a quantidade de pena aplicável, dentro dos limites previstos;

III - o regime inicial de cumprimento da pena privativa de liberdade;

IV - a substituição da pena privativa da liberdade aplicada, por outra espécie de pena, se cabível. 
função judicial é, como a legislação, tanto criação quanto aplicação do Direito. (KELSEN, 1992, p. 138).

Ainda dentro do campo da hermenêutica metodológica, quanto ao sujeito a interpretação podia ser autêntica. "Interpretação autêntica é a que se realiza pelo legislador, através de outra disposição legislativa, contextual ou posterior à lei interpretada". (FRAGOSO, 2006, p. 99). Assim sendo, dentro desta concepção metodológica da hermenêutica, o próprio poder legislativo no momento em que elabora a norma penal declina no próprio texto da lei o seu significado, podendo ser também posterior, sendo esta a interpretação efetuada depois de ditada a lei, servindo para clarear possíveis incertezas e obscuridades.

"Por fim a interpretação pode ser doutrinária, quando constituída da communis opinio doctorum, ou seja, do entendimento dado aos dispositivos legais pelos escritores ou comentadores do Direito". (MIRABETE, 2003, p. 51). Não produziam um enunciado vinculante, uma vez que não possuíam caráter normativo, sem falar na diversidade de pensamentos o que dificulta uma unificação necessária para a concretização da segurança jurídica.

Por fim, nesta concepção de hermenêutica metodológica, a interpretação também pode ser judicial. "Interpretação judicial é a realizada pelos tribunais nos julgamentos que proferem. Constitui o que se chama de jurisprudência". (FRAGOSO, 2006, p. 100). Não vincula, senão para o caso concreto, no entanto cria precedentes em questões semelhantes, tendo força obrigatória para o caso concreto desde que sobrevenha à coisa julgada e esteja coberta pela imutabilidade. Se ultrapassado o prazo de recurso faz coisa julgada material.

Continuando a análise sobre a hermenêutica metodológica, quanto aos meios ou métodos empregados a interpretação podia ser gramatical, também chamado literal ou filológico, que se atém exclusivamente às palavras da lei. "Examina-se a "letra da lei", em sua função gramatical, quanto ao seu significado no vernáculo". (MIRABETE, 2003, p. 51). O intérprete, baseado nos conhecimentos de gramática, examinava, por exemplo, a pontuação, a posição dos vocábulos e o seu significado, examina somente a fórmula verbal usada pelo legislador. Por este meio faz-se uma análise do texto legal verificando o que dizem as palavras da norma. Devia ser levado em consideração que nenhuma palavra na lei era supérflua, bem como que, em regra, as expressões empregadas nas normas tinham significado 
técnico e não vulgar, sem falar no fato de que o singular não exclui o plural e o emprego do gênero masculino não exclui o feminino.

Assim dizendo, essa interpretação era insuficiente por si só, uma vez que não alcançava as transformações da vida social, a diversidade das circunstâncias, os inúmeros fenômenos sociais que ao Direito não podem passar despercebidos. De fato, ainda nesta visão metodológica da hermenêutica, o intérprete não devia ficar atrelado somente à letra da lei, mas devia buscar o seu real sentido dentro do significado intrínseco da norma.

\begin{abstract}
A justa aplicação da norma requer do intérprete a descoberta do significado intrínseco, de que ela é o portador. Por outras palavras: requer dele que não se fique pela letra da lei, mas decifre o sentido apropriado, o espírito que nela se guarda. Já isto nos adverte que o significado próprio da norma é superior às intenções dos homens que a formulam. (VECHIO, 1948, p. 56).
\end{abstract}

Ligado a esse processo, seguindo a visão da hermenêutica metodológica, se encontrava o método lógico-sistemático, que nos conduzia a confrontar a disposição em análise com outras normas constantes em todo o ordenamento jurídico, referentes ao mesmo assunto, e, muitas das vezes, com os princípios gerais do Direito. O intérprete servia-se dos exames de determinados institutos e até do Direito comparado. "A norma não é um princípio isolado, mas compõe um sistema que o intérprete não pode deixar de considerar, embora a classificação na lei não seja um elemento decisivo". (FRAGOSO, 2006, p. 102). Tratava-se, de um método obrigatório, uma vez que é impossível se abstrair o verdadeiro sentido da norma penal se este não for analisado e compreendido no contexto maior do ordenamento normativo globalizado. "O exegeta analisa o dispositivo legal no sistema no qual ele está contido, e não de forma isolada”. (GRECO, 2011, p. 38).

Ainda percorrendo os caminhos da hermenêutica metodológica, devemos mencionar o método lógico-sociológico. Não se buscava aqui, obrigatoriamente, a vontade do legislador, como faziam os subjetivistas. Inúmeras são possibilidades de acontecimentos sociais supervenientes e o legislador não as anteveria em razão das múltiplas transformações políticas, sociais e culturais. A letra da lei fica estática, entretanto, o direito sobrevive, através de uma interpretação sensível às contingências da atualidade. A norma, segundo esta visão, possuía o poder de abraçar hipóteses imprevistas pelo legislador, adaptando-se aos tempos modernos. Seguindo esta hermenêutica metodológica "a interpretação deve buscar a vontade 
da lei, desconsiderando a de quem fez. A lei termina independente de seu passado, importando apenas o que está contido em seus preceitos". (CAPEZ, 2012, p. 52).

Tem-se de igual modo, seguindo a esteira da hermenêutica metodológica, o método teleológico, que na lição de Carlos Maximiliano se trata de ser "o melhor, o mais seguro na maioria das hipóteses". (MAXIMILIANO, 1941, p. 19).

A interpretação teleológica consiste em indagar a finalidade da lei, levando em consideração os motivos e as finalidades que determinaram a sua produção. Os problemas hermenêuticos metodológicos se situam em uma relação entre emissores e receptores das normas. Fala-se, então, da interpretação teleológica, isto é, nas quais se postulam os fins. No caso do Direito Penal, a finalidade é, através das normas incriminadoras, a proteção de bens jurídicos fundamentais selecionados a luz de um critério político pelo legislador. Para a hermenêutica metodológica, em especial em seu método teleológico, a finalidade da lei, uma vez identificada, se sobrepunha à letra da norma, instrumento verbal do Direito, muitas das vezes injusta se aplicada automaticamente. Conclui-se desta maneira que a "interpretação lógica ou teleológica: busca-se na vontade da lei, atendendo-se aos seus fins e à sua posição dentro do ordenamento jurídico". (CAPEZ, 2012, p. 53).

De acordo com os princípios da hermenêutica metodológica, a interpretação, afinal, conduzia a uma única conclusão apesar da coexistência de vários métodos. De acordo com o caso concreto caberia, dentro desta concepção, ao magistrado a escolha entre este ou aquele método de interpretação, conforme a que se melhor apresentasse, para a segurança de suas decisões. Entretanto, entre a letra e o espírito, na hipótese de contraste, não há dúvidas que deveria optar por utilizar o último.

No que diz respeito ao resultado, segundo esta concepção metodológica da hermenêutica, o intérprete, após fazer uso dos meios já estudados, chegaria a um resultado interpretativo o qual podia ser declarativo, restritivo ou extensivo.

"Na interpretação declaratória, o interprete não amplia nem restringe o seu alcance, mas apenas declara a vontade da lei". (GRECO, 2011, p. 39). Não se vê nestes casos a necessidade de conferir um sentido mais amplo ou restrito, ou seja, não se precisa restringir ou estender o entendimento porque está escrito. A interpretação restritiva, nesta visão metodológica, "é aquela em que o intérprete diminui, restringe o alcance da lei, uma vez que esta, à primeira vista, disse mais do 
que efetivamente pretendia dizer (lex plus dixit quan voluit), buscando, dessa forma, aprender o seu verdadeiro sentido". (GRECO, 2011, p. 39). Assim sendo, se impõe quando é preciso restringir o significado da lei, por causa da amplitude de sua expressão literal não corresponder com seu real sentido, ou seja, quando o texto da lei disser mais que a sua vontade, surgindo a necessidade de restringir o alcance de suas palavras.

Ainda percorrendo os caminhos da hermenêutica metodológica, a interpretação extensiva ocorre quando é necessário ampliar o sentido da norma para além do contido na sua letra, pois nesse caso o texto da lei disse menos do que deveria dizer. A chamada interpretação analógica é uma espécie de interpretação extensiva e se traduz em uma extensão do conteúdo da norma aos casos análogos correspondentes à vontade da lei. O legislador, por não poder prever todas as situações que poderiam ocorrer na vida em sociedade, permitiu expressamente a

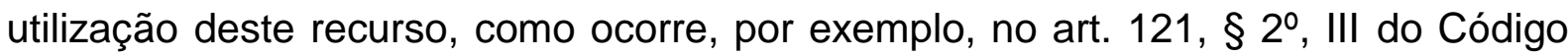
Penal quando dispõe, "se o homicídio é cometido: com emprego de veneno, fogo, explosivo, asfixia, tortura ou outro meio insidioso ou cruel, ou de que possa resultar perigo comum". Quando a lei se refere a "outro meio" está a permitir uma interpretação analógica, podendo o intérprete ampliar a aplicação da lei a casos similares. "Podemos perceber que a fórmula casuística - com emprego de veneno, fogo, asfixia, tortura - o Código fez seguir uma fórmula genérica - ou outro meio insidioso ou cruel, ou de que possa resultar perigo comum". (GRECO, 2011, p. 41). A distinção entre interpretação analógica e analogia está no fato de ser este último um processo de integração da lei e a outra um meio de interpretar o conteúdo normativo. "Podemos, portanto, entender que a interpretação extensiva é o gênero, no qual são espécies a interpretação extensiva em sentido estrito e a interpretação analógica". (GRECO, 2011, p. 41).

A interpretação analógica é permitida toda vez que houver uma fórmula casuística seguindo uma cláusula genérica, a qual deve ser interpretada de acordo com os casos anteriormente mencionados na forma pretendida pela vontade da lei.

A visão da hermenêutica metodológica que determinava ao intérprete visualizar o fim da norma para depois aplicá-la ao caso concreto, que aproximava o Direito da norma e não da Ética, que deixava a dignidade da pessoa humana para um segundo plano, que atribuía um valor absoluto às normas positivadas e não viam 
nos princípios o seu valor normativo, que se estabelecia em uma relação de causa e efeito, sujeito e objeto, representa uma visão ultrapassada, uma vez que a aplicação da lei deverá atender antes de tudo o indivíduo e a sociedade a quem ele serve, por isso, o hermeneuta deve focar seu horizonte interpretativo na compreensão da pessoa humana dentro de sua realidade histórica e cultural. Assim o problema jurídico que envolve uma situação de natureza valorativa deve ser compreendido, no entanto, dentro da hermenêutica filosófica devemos entender a dignidade da pessoa humana como princípio legitimador do Direito colocando-a no centro das discussões jurídicas. Neste caminho, o Direito deixa de ser visto como o único instrumento para a solução dos casos apresentados, devendo ser entendido como mais um instrumento posto a disposição do aplicador do Direito.

"Assim, o problema jurídico, que envolve situação de natureza valorativa deve ser compreendido". (CAMARGO, 2011, p. 13). Compreender é buscar o entendimento do fenômeno jurídico, buscando valores que extrapolam os limites da lei sendo aí o local onde se verifica o respeito ao princípio da dignidade da pessoa humana. Esta compreensão foge de uma mera relação de causa e efeito. Para que se verifique a solução do caso jurídico não bastará detectar-se o fato e encaixá-lo em uma norma positivada e abstrata dando-lhe concretude por meio de uma operação de subsunção da premissa menor à premissa maior, pois se trata de uma operação meramente formal. O Direito é compreendido em valores, sendo que a norma, fria e estática está relacionada a uma situação histórica na qual fazem parte o interprete o fato e a norma.

Cabe falarmos em hermenêutica nesta área do conhecimento que não se submete à certeza da investigação científica. $\mathrm{E}$ o Direito não foge à regra. $\mathrm{A}$ hermenêutica jurídica refere-se assim, a todo um processo de interpretação e aplicação da lei que implica a compreensão total do fenômeno que requer solução. (CAMARGO, 2011, p. 15).

Portanto, imperioso afirmar, que não se fala em compreensão como uma metodologia, na qualidade de condição técnica formalística de uma conduta, mas um processo que verificamos em seu desdobramento e que tem como pressuposto investigar uma realidade histórica, uma tradição.

O Direito como construção do homem, deve ser compreendido e não explicado a partir de relações de causa e efeito, ou através de métodos de interpretação dirigidos às normas somente, como se para cada problema social 
existisse somente uma verdade e uma norma específica que conduz a uma única solução. Ao contrário, a existência do Direito, enquanto norma corresponde à sua compreensão para a qual se abrem várias possibilidades interpretativas. Assim sendo a interpretação passa a ser uma ação que procura a compreensão do ser. $O$ Direito, enquanto instrumento de transformação, diante da evolução da sociedade, não pode usufruir de métodos engessados a fim de solucionar os conflitos. Não cabe descobrir a solução na interpretação exclusiva da lei uma vez que a realidade dos fatos se mostra imprevisível. A impossibilidade de um método alcançar a verdade é a conclusão inevitável uma vez que esta verdade não se encontra na lei, mas sim na própria realidade do mundo pré-compreendido pelo intérprete.

A existência do Direito conforma-se assim, a uma tradição cultural determinada, mas que não pode ser encarada sob uma perspectiva reducionista, uma vez que admite valores universais válidos também para as outras épocas e outros lugares. Compreender é indagar sobre as possibilidades do significado de um acontecer próprio das relações humanas. E, nesse sentido, que acreditamos que o direito só existe quando compreendido. (CAMARGO, 2011, p. 20).

De fato, a compreensão do ser condicionado à sua situação no mundo e sua realidade histórica e cultural tende a ser o caminho a ser percorrido pelo hermeneuta, deixando para traz o velho paradigma de interpretação de normas por meio de métodos interpretativos uma vez que é impossível fazer uma interpretação sem que a visão do aplicador esteja direcionada ao ser, ou melhor, à compreensão deste ser inserido em um mundo pré-compreendido. Obviamente o julgador deve ter a compreensão do mundo e da realidade deste mundo antes do momento de decidir o caso, bem como buscar a compreensão do ser inserido neste mundo e sua real dimensão, visando a solução para o caso tendo como norte a dignidade da pessoa humana, uma vez que esta aqui assume o cerne das discussões jurídicas e não a norma. Para isso necessário de faz um pré-compreensão do mundo e sua realidade histórica e cultural, suas tradições e costumes. "O que ocorre é que, desde sempre, o "sujeito interpretante" está inserido no mundo, em um mundo linguisticamente constituído, de onde é impossível a emergência de um cogito desindexado da tradição". (STRECK, 2009, p. 236).

Abre-se, assim, um campo de ação em que a compreensão é ontologicamente fundamental e antecede qualquer ato de existência. A compreensão sustenta a interpretação; é contemporânea de nossa 
existência e está presente em todo ato de interpretar, cuja essência está unida por vínculos fortes às potencialidades concretas do ser, no horizonte da situação que cada um ocupa no mundo. (MELLO, 2008, p. 105).

"A consciência da história efetiva é a consciência da situação hermenêutica, portanto, do momento de realização da compreensão". (CAMARGO, 2011, p. 31). Assim sendo deve o hermeneuta possuir uma compreensão histórica cultural do mundo e da tradição ao qual está inserido para poder compreender o ser também inserido neste mundo e nesta tradição. Não cabe como missão da hermenêutica descobrir métodos para uma correta interpretação da norma, mas refletir sobre a realidade histórica e cultural a que está inserido, buscando na compreensão do ser inserido nesta mesma realidade a solução para o caso proposto. O indivíduo compreende a si mesmo através da consciência que tem de sua situação histórica, sendo esta situação a mesma em que está inserida o caso concreto. A compreensão não é nunca um trabalho subjetivo em relação a um objeto, mas sim, pertence à própria história, assim, afasta-se do trabalho do hermeneuta todo pensamento que estabeleça uma relação entre sujeito e objeto. "Feito isto, elimina qualquer consideração referente ao grau de subjetividade de intérprete frente ao máximo de objetividade que se requer para o conhecimento da coisa". (CAMARGO, 2011, p. 36). O que o hermeneuta faz é se inserir em um processo histórico do qual da mesma forma que àquele envolvido no caso concreto também faz parte.

\footnotetext{
A compreensão que faz parte do modo de ser-no-mundo, antecipa qualquer tipo de explicação lógico-semântica, não no sentido temporal, cronológico. Porque estamos no mundo há uma compreensão que se antecipa a qualquer tipo de explicação. Temos uma estrutura do nosso modo de ser que é a interpretação. Por isso, sempre interpretamos. O horizonte do sentido é-nos dado pela compreensão que temos de algo. O ser humano é compreender. Ele só se faz pela compreensão. Ele só se dá pela compreensão. Compreender é um existencial, que é uma categoria pela qual o homem o homem se constitui. A facticidade, a possibilidade, a compreensão são alguns desses existenciais. O fundamento do compreender é próprio do homem. (STRECK, 2009, p. 201).
}

De fato, a compreensão do ser em sua realidade histórica e cultural não permite o subjetivismo por parte do hermeneuta, pois se trata de ter como ponto de referência a própria significação histórica assumida, tendo por fim a prevalência da dignidade da pessoa humana como princípio e fim do trabalho hermenêutico. O Juiz está, portanto inserido em uma situação hermenêutica a qual ele também faz parte, vivenciando a mesma experiência histórica de ser e estar no mundo. Mas a 
compreensão não faz parte de uma busca do passado, mas sim na determinação universal do ser inserido em sua realidade atual, historicamente condicionada, tratando-se da experiência humana da qual todos nós participamos.

Vale destacar que essa posição pró-ativa do julgador não significa um retorno ao subjetivismo, tampouco perfaz decisões proferidas ao acaso. Pelo contrário, o magistrado está inserido numa situação hermenêutica, através do circulo hermenêutico, vivenciando uma tradição que é um patrimônio comum do homem inserido no ser-no-mundo. Portanto, o pensamento jurídico está em harmonia com um sistema aberto, já que a fundamentação jurídica é sem fundo, abissal e a sua determinação está relacionada a uma abertura de possibilidades. Somente após esta fase hermenêutica que o intérprete poderá adentrar na argumentação jurídica. (MELLO, 2008, p. 110).

$\mathrm{Na}$ missão do julgador de dar uma solução para o caso concreto a interpretação parte de um conjunto de conceitos e conhecimentos anteriores e sedimentados que nos possibilita obter suas conclusões com o mínimo de previsibilidade. Analisando historicamente a questão, a tradição cumpre este papel. No que diz respeito especificamente ao mundo jurídico, verificamos toda uma tradição formada por julgados, formalidades e princípios que acabam norteando o intérprete.

Os princípios extraídos da doutrina e da jurisprudência conhecidos, portanto, dos profissionais e estudiosos do direito, permitem que a dialética se instaure dentro de limites que the retirem qualquer espécie de arbitrariedade, conferindo-lhe, inclusive, considerável fator de previsibilidade. (CAMARGO, 2011, p. 51).

"A propósito desta área circunscrita na qual atua o direito e que, por sua vez, delimita um campo próprio de interpretação é que podemos falar do "círculo hermenêutico"'. (CAMARGO, 2011, p. 52). A interpretação se funda em uma visão prévia, assim sendo, toda a interpretação se encaixa no comportamento de compreender já devendo ter compreendido o que se quer interpretar. Concluímos então que a circularidade hermenêutica se funda na pré-compreensão apoiada sobre o sentido daquilo que buscamos compreender. A pré-compreensão legitima-se na tradição como processo histórico que o intérprete está inserido. "E assim, na "compreensão da pré-sença projeta seu ser para possibilidades"”. (CAMARGO, 2011, p. 53). 
A hermenêutica filosófica surge como horizonte de um problema naturalmente intrínseco às questões humanas, dizendo respeito ao fato de nos depararmos frente à totalidade do mundo como contexto histórico e vital da própria existência humana do ser. "A partir disto, a pergunta acerca de como é possível o conhecimento e quais são as suas condições, passa a ser um problema menor dentro da globalidade da questão referente ao compreender da existência do horizonte de outros existentes". (STRECK, 2009, p. 195). A opção pela hermenêutica filosófica amplia a visão do intérprete quando possibilita a evolução das respostas do Direito aos fatos da vida. O apego excessivo ao legalismo acaba por encobrir o melhor sentido do processo interpretativo, ou seja, a transformação social através de decisões que respaldam as garantias constitucionais sob o ponto de vista de cada fato, a partir da compreensão do intérprete do mundo.

Para descobrir a verdade de cada caso, pela hermenêutica de cunho filosófico, há que se ter em mente as pré-compreensões do intérprete sobre a realidade histórica e cultural, onde se verifica uma tradição. Pela hermenêutica de cunho metodológico, a verdade é aquela contida na lei, mesmo que as particularidades do caso apontem para um caminho diverso. A verdade já existe antes mesmo do caminho do hermeneuta e não depende da lei, não está na interpretação da lei, mas sim na compreensão do ser inserido em sua realidade histórica.

\footnotetext{
O que nos é dado a entender acerca da existência humana, com sua finitude, sua mobilidade, sua projeção para o futuro e, em suma, sua precariedade, tudo isso pertencerá à forma primordial do compreender. Interpretar é, pois, hermenêutica, e hermenêutica é compreensão e através dessa compreensão se produz o sentido. Não há um sentido escondido na norma que possa ser alcançado de maneira essencial, tampouco há um sentido imanente que liga o significante ao significado como um objeto que possa ser buscado através de um processo interpretativo-objetivante pelo sujeito cognoscente. (STRECK, 2009, p. 195).
}

Enquanto na superada hermenêutica metodológica buscava-se estabelecer uma prática de interpretação limitada a métodos direcionada a identificar a finalidade da norma, a hermenêutica filosófica busca inserir a interpretação num contexto de caráter existencial com características do acontecer da tradição histórica, cultural e temporal do ser, onde o interpretar passa a ser uma compreensão do ser. "O que a nova hermenêutica irá questionar é a totalidade do existente humano e sua inserção 
no mundo". (STRECK, 2009, p. 195). Em se tratando da hermenêutica filosófica, verifica-se aqui um campo onde se exige um comprometimento do intérprete. As verdades jurídicas não dependem, dentro deste novo paradigma hermenêutico, de métodos, pois dentro deste sistema metodológico o que se verificava era a subjetividade do intérprete, assim sendo o que se entendia como segurança jurídica, na verdade se tratava de uma "insegurança jurídica". Na hermenêutica filosófica não há lugar para subjetivismo, uma vez que aqui o que se busca é a compreensão do ser, dentro de uma relação que se dá entre sujeito e sujeito, ambos atrelados a uma mesma realidade histórica. $O$ julgador já possui uma pré-compreensão do seu mundo, inserido dentro das tradições culturais historicamente construídas, daí passa a compreender o ser inserido neste mundo e sua realidade histórica e factual, buscando na compreensão deste ser a solução que melhor dignifique a dignidade da pessoa humana. "Portanto, em sua essência, a hermenêutica não é um método, mas sim uma filosofia transcendental que pode ser aplicada ao Direito". (MELLO, 2008, p. 110).

\begin{abstract}
Só é possível interpretar se existe a compreensão. E esta depende da précompreensão do intérprete. Por isto a compreensão necessariamente será um existencial. $O$ intérprete não se pergunta por que compreende, porque ao compreender, já compreendeu. Daí a importância da tradição, lugar de inserção do homem, como ser-no-mundo e ser-com-outros. Impossível negar a facticidade. Ao tentar negá-la esta já atuou no modo de compreender-interpretar o mundo. (STRECK, 2009, p. 225).
\end{abstract}

A hermenêutica filosófica busca o conhecimento através da compreensão do ser inserido em uma realidade histórica, considerando a pré-compreensão do intérprete, assim sendo as pré-compreensões do intérprete já antecipam o caminho a ser seguido. Nesse sentido, ao eleger os métodos que descobrem a verdade dos textos, a hermenêutica metodológica divorcia-se da realidade que se apresenta.

A historicidade é o local da pré-compreensão, condição de possibilidade para qualquer interpretação, uma vez que é impossível a interpretação isolada de uma compreensão já existente da realidade histórica e cultural a qual se encontra o intérprete. Desta maneira somente será possível a verificação de uma interpretação se constatarmos a compreensão. "Dizendo de um modo mais simples: só interpreto se compreendo; só compreendo se tenho pré-compreensão, que é constituída de uma estrutura prévia, visão previa e concepção prévia, que já une todas as partes do "sistema"”. (STRECK, 2009, p. 218). 
A hermenêutica metodológica, calcada em regras ou métodos, não se mostra suficiente diante de questões mais complexas uma vez que é impossível prever os múltiplos acontecimentos da vida humana. Diante da realidade, tendo por base uma hermenêutica de cunho filosófico, o intérprete busca a compreensão do fato, numa perspectiva de abertura e de aproximação à realidade, inversamente no que ocorre na hermenêutica metodológica, onde os métodos repetitivos suplantam a realidade em nome da afirmação da validade da lei. No mundo dos fatos, caracterizados pelos inúmeros avanços sociais, a hermenêutica filosófica singulariza cada interpretação, e demonstra a impossibilidade de se prever resultados através de regras ou de métodos interpretativos.

\begin{abstract}
Assim, a hermenêutica deixa de ser metódica e normativa para ser filosófica. A linguagem deixa de ser instrumento e veículo de conceitos deixando, assim, de "estar a disposição do intérprete" - para ser a condição de possibilidade da manifestação do sentido. Esse sentido não exsurge porque o intérprete utiliza este ou aquele método. Tampouco o intérprete interpreta por partes, como que a repetir as fases da hermenêutica clássica: primeiro, subtilitas intelligendi, depois a subtilitas explicandi, e, por último a subtilitas applicandi. (STRECK, 2009, p. 218).
\end{abstract}

A superação da hermenêutica metodológica pela hermenêutica filosófica representa a superação do subjetivismo, pois a compreensão do ser inserido em uma realidade histórica a qual o intérprete já está inserido e atrelado promove a busca da essência, a humanização do Direito que se afasta da norma e se aproxima da dignidade da pessoa humana.

\begin{abstract}
O que se procura com a superação da filosofia da consciência, da relação sujeito-objeto, do subjetivismo, é a busca do homem em sua essência, como possibilidade e modo de ser-no-mundo, ou seja, é o caminho em direção a uma humanização do Direito. É o caminho para a (de)sentificação do Direito, já que um ente não pode fundar os entes. Por isso é que o fundamento é um existencial. É a partir da hermenêutica como modo de serno-mundo que o Direito deve procurar caminhar por uma área de valores peculiares, subtraídos à lógica formal do direito positivo. (MELLO, 2006, p. 169).
\end{abstract}

O elemento histórico constitui um valioso subsídio para o hermeneuta. Necessário é verificar na sociedade os caracteres culturais que influenciam os próprios institutos jurídicos, ora passageiros, ora perenes, apontando assim, na trajetória do tempo, sua subordinação às exigências e transformações sociais. Fazse, uma compreensão das condições históricas. Para procurar a origem da lei, o 
intérprete deve percorrer os caminhos de um historiador podendo utilizar recursos normativos, como os debates dos parlamentares, a exposição de motivos, sem falar nos acontecimentos históricos. A análise deste conjunto nos conduz aos motivos ocasionais que marcaram efetivamente a origem da norma. Alguns dispositivos legais ainda em vigor em nosso ordenamento jurídico penal devem ser revistos, pois ainda guardam aspectos contrapostos a este entendimento. É o caso, por exemplo, da contravenção penal de vadiagem, disposta no Decreto-lei 3.688/41 em seu artigo 59 com a seguinte redação,

Entregar-se alguém, habitualmente à ociosidade, sendo válido para o trabalho, sem ter renda que lhe assegure meios bastantes de subsistência, ou prover a própria subsistência mediante ocupação lícita:

Pena - prisão simples, de 15 (quinze) dias a 3 (três).

Importante salientar que buscando no caso em estacada uma compreensão histórica, esta nos lavará a concluir pela inaplicabilidade deste dispositivo nos dias atuais.

Primeiramente, a existência desta contravenção se deve a uma questão histórica. Data o decreto lei 3.688 de 3 de outubro de 1941, ano em que se verificava um fenômeno social, em especial nas grandes metrópoles. Ocorre que em 1988 sobreveio a abolição da escravatura no Brasil, com isso muitos daqueles libertos migraram para as grandes cidades causando um grande aglomerado de pessoas, até certo ponto, indesejáveis para os padrões de uma elite dominante. Neste diapasão, o dispositivo em comento foi utilizado como forma de retirar de circulação tais pessoas. Posteriormente o mesmo dispositivo foi utilizado para retirar das ruas prostitutas, travestis e viciados. Nos dias atuais, com a vigência do Estado Democrático de Direito erguido pela Carta Magna de 1988 e a consagração das liberdades, a contravenção penal de vadiagem perdeu seu significado.

Neste sentido, o julgador, possuindo uma pré-compreensão do momento histórico a qual está inserido e buscando a compreensão do ser, de igual maneira inserido no mundo, por isso se vislumbra uma relação entre sujeito e sujeito, não aplicará o dispositivo, uma vez que não representa mais um elemento de proteção da dignidade da pessoa humana. Cumpre ressaltar que a compreensão do ser inserido no mundo histórico atual, visualizando aquele que não queira trabalhar nem tenha renda para se sustentar não pode por si só levá-lo a uma condenação uma 
vez que sua conduta em nada veio a ofender bens jurídicos de terceiros, e mais, dentro de nossa realidade histórica, um dos principais aspectos de proteção da dignidade da pessoa humana está na proteção de sua liberdade, inclusive na liberdade que a pessoa deve ter de não fazer nada e entregar-se à ociosidade.

De outro lado, se analisássemos o caso em tela pelo olhar da hermenêutica metodológica, atrelada a um positivismo normativista, cairíamos em um retrocesso onde o império legalista se impunha e a lei deveria ser aplicada uma vez que neste sistema superado a supervalorização da norma afasta o Direito da dignidade da pessoa humana, impondo a triste noção de que não existe Direito que não seja o positivado e que o intérprete deve interpretar a norma e depois aplicá-la ao caso concreto, em uma relação entre sujeito e objeto.

Enfim, a superação da hermenêutica metodológica pela hermenêutica filosófica representou uma mudança de paradigma uma vez que se superou uma relação antes existente entre sujeito-objeto, vislumbrando-se agora uma relação entre sujeito e sujeito, onde a compreensão do ser inserido no mundo historicamente compreendido e pré-compreendido conduzirão o julgador a uma variedade de possibilidades possíveis, assim sendo, o direito positivado passa a ser mais uma possibilidade para o legislado e não a única. O centro das discussões jurídicas passa a ser não mais a norma, mas a compreensão do ser dentro de sua realidade histórica no mundo, fazendo com que o ideal da busca da dignidade da pessoa humana não se apresente mais ligado aos velhos dogmas positivistas.

Não se deve pensar que o Direito Penal exija uma forma peculiar de interpretação, que extrapole a rotina da interpretação jurídica em geral, até porque, como foi visto, a hermenêutica metodológica foi superada pela hermenêutica filosófica que, dentre outros méritos, enalteceu a dignidade da pessoa humana como centro das discussões jurídicas. Uma interpretação metodológica da norma penal representa um retrocesso no que diz respeito aos mecanismos de proteção da dignidade da pessoa humana, pois colocam a lei como centro das discussões jurídicas e deixam para segundo plano a proteção da dignidade da pessoa humana.

Dentro de uma concepção metodológica, havendo dúvida sobre duas ou mais formas diferentes de se aplicar a norma penal, deve-se optar pela solução que se apresente como a mais benigna para o réu. É o princípio do favor rei. Quer isto 
significar que a incerteza em relação qual solução possível não deve ocasionar prejuízo para o réu.

\begin{abstract}
A certeza do direito penal mínimo no sentido de que nenhum inocente seja punido é garantida pelo princípio do in dubio pro reo. É o fim perseguido nos processos regulares e suas garantias. Expressa o sentido de não culpabilidade do acusado até que se prove o contrário: é necessária a prova - quer dizer, a certeza, ainda que seja subjetiva - não da inocência, mas da culpabilidade, não se tolerando a condenação, mas exigindo-se a absolvição em caso de incerteza. (FERRAJOLI, 2010, p. 103).
\end{abstract}

No entanto se examinarmos o mesmo caso sob o olhar da hermenêutica filosófica, esta crise interpretativa estará superada, pois a compreensão do ser, inserido em uma realidade histórica, permitirá a solução para o caso sem a perda de tempo existente na discussão entre este ou aquele método interpretativo, até porque, não está na lei a única forma de solução para o caso concreto, ela representa apenas mais um instrumento posto a disposição do juiz, uma vez que este buscará não a interpretação da lei para a solução, mas sim na compreensão do ser no mundo, dentro de sua historicidade e atenderá a dignidade da pessoa humana, longe de qualquer subjetivismo.

Por fim, e para afirmar a desconstrução da hermenêutica metodológica, podemos afirmar que a utilização de métodos de interpretação sempre se mostrou precário frente à ausência de regras que ordenam uma hierarquização entre eles, permitindo a possível utilização de uma interpretação arbitrária, ou seja, estes métodos funcionam como justificativas para legitimar resultados que o intérprete se propõe a alcançar. Ou seja, a fragilidade dos métodos de interpretação deriva da inexistência de uma regra ordenadora de sua aplicação em cada caso. Aqui se verifica uma crise na interpretação da norma, pois a utilização de métodos interpretativos para buscar o sentido da norma, desvinculado de uma compreensão do ser inserido em uma realidade histórica e cultural permite não somente a verificação de uma relação de causa e efeito, mas principalmente de uma possibilidade para o subjetivismo que deve ser a todo instante repudiado.

Quando falamos em crise na interpretação da norma penal estamos querendo dizer que o sistema penal se vê em crise sempre que o intérprete deixa para um segundo plano a dignidade da pessoa humana, a compreensão do ser inserido em sua realidade história, para concentrar seu trabalho na interpretação da norma por meio de métodos interpretativos utilizados para se chegar a uma 
"solução". Como vimos tais métodos ou regras interpretativas se mostram precários frente ao verdadeiro desafio do hermeneuta que deve estar relacionado com a compreensão do mundo e sua realidade histórica e com a compreensão do ser inserido neste mundo para buscar a solução do caso penal.

A nosso ver, o entendimento inserido na hermenêutica filosófica tem o condão de superar esta crise, consagrando um novo paradigma para o intérprete que buscará a compreensão do caso penal, por meio de uma pré-compreensão do mundo historicamente condicionado às tradições, por uma compreensão do ser inserido neste mundo ao qual o próprio intérprete também está inserido, livre de todo e qualquer subjetivismo, não atrelado a nenhum tipo de método, uma vez que aqui o norte para o hermeneuta se trata da dignidade da pessoa humana, assim sendo, o Direito passa a ser visto como mais um instrumento posto à disposição do hermeneuta e não como a única solução possível.

O Estado Democrático de Direito, a nosso ver, não se coaduna com uma interpretação que não busque uma compreensão do ser, quando na busca pela resolução de um conflito. Por mais que a lei tenha sido elaborada em determinada época, é natural que os anseios da sociedade evoluam diversamente do texto legal, que permanece estagnado, cabendo ao hermeneuta uma interpretação aberta às transformações que a realidade apresenta. A evolução da sociedade requer uma compreensão ampla dos fatores sociais, assim sendo a recepção da hermenêutica filosófica amplia a visão do intérprete trazendo consigo a possibilidade de maior valorização e proteção dos direitos fundamentais, em especial a dignidade da pessoa humana, fundamento maior do Estado Democrático de Direito.

Notamos na atual Constituição a sua capacidade de influenciar as relações sociais, devido ao conjunto variado de valores por ela guarnecido, representa a modificação da estrutura do Estado para uma Democracia aberta às discussões que remontam à própria sociedade. A transformação social é uma realidade, assim sendo torna-se necessária a opção pela hermenêutica filosófica que valorize as concepções do intérprete, enquanto cidadão, que desde sempre já se posiciona em sua realidade cultural e histórica diante da lei, tendo a possibilidade de criar oportunidades para as realizações, antes obstruídas pelo positivismo que elegeu uma hermenêutica de cunho metodológico. 
A hermenêutica filosófica, segundo nosso entendimento, deve ser considerada o modelo ideal na busca pela verdade por parte do hermeneuta, uma vez que investiga a verdade através das pré-compreensões que o intérprete já possui do mundo. Tais pré-compreensões se perfazem através da tradição e ampliam o movimento das relações sociais. Em sentido oposto a hermenêutica metodológica propõe a busca de uma "verdade" já contida na lei, descompromissada com a realidade trazida pelo intérprete. Enfim, podemos concluir que a hermenêutica filosófica representa a opção de argumentação mais compatível às necessidades reais da sociedade e com os ideais de humanidade apregoados pelo Estado Democrático de Direito.

A hermenêutica filosófica se alinha à Constituição Federal de 1988, que consagrou um rol de garantias inerentes à dignidade da pessoa humana, que, na realidade, só podem ganhar efetividade no mundo dos fatos através de uma hermenêutica de cunho filosófico. A hermenêutica metodológica, intrínseca ao modelo positivista não representa transformação social para o Direito, na medida em que busca unificar a interpretação do caso concreto e, assim, impede a dinâmica do Direito quando se deparada com situações distintas.

\section{REFERÊNCIAS}

BECCARIA, Cesare. Dos delitos e das penas. Tradução: Paulo M. Oliveira. 2. ed. São Paulo: Exposição do Livro, 1983.

BRUNO, Anibal. Direito penal: parte geral. 5. ed. Rio de Janeiro: Forense, 2003. v. 1.

CAMARGO, Margarida Maria Lacombe. Hermenêutica e argumentação. 3. ed. Rio de Janeiro: Renovar, 2011.

CAPEZ, Fernando. Curso de direito penal: parte geral. 16. ed. São Paulo: Saraiva, 2012.

COSTA, Álvaro Mayrink. Direito penal: parte geral. 7. ed. Rio de Janeiro: Forense, 2005. v. 1.

FRAGOSO, Heleno Cláudio. Lições de direito penal. 17. ed. Rio de Janeiro: Forense, 2006. 
FERRAJOLI, Luigi. Direito e razão: teoria do garantismo penal. Tradução: Ana Paula Zomer Sica, Fauzi Hassan Choukr, Juares Tavares e Luiz Flávio Gomes. 3. ed. São Paulo: Revista dos Tribunais, 2010.

GRECO, Rogério. Curso de direito penal: parte geral. 13. ed. Niterói: Impetus, 2011.

GUSMÃO, Paulo Dourado. Introdução ao estudo do direito. 9. ed. Rio de Janeiro: Forense, 1982.

KELSEN, Hans. Teoria geral do direito e do Estado. Tradução: Luiz Carlos Borges. São Paulo: Martins Fontes, 1992.

KELSEN, Hans. Teoria pura do direito. Tradução: João Baptista Machado. São Paulo: Martins Fontes, 2006.

MAXIMILIANO, Carlos. Hermenêutica e aplicação do direito. Rio de Janeiro: Freitas Bastos, 1941.

MELLO, Cleyson de Moraes. Hermenêutica e direito. Rio de Janeiro: Freitas Bastos, 2006.

MELLO, Cleyson de Moraes. Introdução à filosofia do direito, à metodologia da ciência do direito e hermenêutica contemporânea. Rio de Janeiro: Freitas Bastos, 2008.

MIRABETE, Julio Fabrini. Manual de direito penal. 21. ed. São Paulo: Atlas, 2003. v. 1.

STRECK, Lenio Luiz. Hermenêutica jurídica e(m) crise: uma exploração hermenêutica da construção do direito. 8. ed. Porto Alegre: Livraria do Advogado, 2009.

VECHIO, Giorgio Del. Lições de filosofia do direito. Tradução: Antônio José Brandão. São Paulo: Saraiva, 1948.

Recebido em 19/12/2019.

Aceito em 19/12/2019. 